\title{
local chapter affairs
}

The purpose of the local chapter affairs column continues to be providing a vehicle for sharing information relevant to local AMS chapters. This article shares a local chapter officer's perspective on the essentials of creating a great local AMS chapter.

Teamwork is the Key: Create a vibrant and healthy chapter environment by putting the needs and goals of your chapter membership ahead of your personal desires and wishes for the chapter. If you are a chapter officer, encourage a get-together with the other chapter officers before the chapter year begins to develop a unique game plan for your chapter and to foster a positive chapter officer climate. Ask AMS headquarters, other chapter officers, and a few people in your area for their advice and opinions. Once the officers have formulated their ideas, find a way to bounce it off your chapter members. A survey is one way to get ideas so you can incorporate chapter member feedback. The October 1997 Bulletin contains an excellent local chapter affairs article on tips on conducting surveys. This article is also available under the local chapter link on the AMS Web site and is part of the Local Chapter Officer's Handbook. Another way to get member buy-in is to outline the proposed chapter schedule via e-mail, your Web site, or in person, and incorporate ideas and changes you receive. If you are a chapter member, provide constructive ideas and suggestions to your chapter officers and help them achieve success. Consider joining forces for a complementary activity with the local astronomical society (Packerland chapter) or team up with the local National Weather Association chapter (Omaha-Offutt chapter). Throughout the year, consider new ways to rejuvenate chapter participation.

Activity Diversity: Each local chapter is unique. Find activities that best match the commitment and desires of your membership. Every chapter has a varying amount of talent right at your fingertips. Potential speakers can be drawn from the local community, scientists visiting the area, and the chapter membership. Many industries and utility companies have speaker's bureaus and/or frequently give tours of their facilities. Every community likely has an emergency manager who could explain preparations and planning for weather-related disasters. Every chapter probably has at least one "computer whiz" who could demonstrate the different weather information that can be found on the Internet. Hosting a conference or symposia is excellent; however, because it requires lots of work, your chapter must strongly support it and be committed to its success.

Other chapter guest speakers have included a representative from a local power company (Central North Carolina); a representative from a state highway department, who discussed snow removal (Puget Sound and Omaha-Offutt); a representative from the International Ice Patrol, which was established after the sinking of the Titanic (NYC/Long Island); and a representative from the National Science Teachers' Association (Denver-Boulder). Other possibilities include the sponsorship of an explorer post (OmahaOffutt), staffing a weather booth at the science museum (Kansas City), the donation of weather instruments to local schools (Arkansas), a weather trivia contest (Wright Memorial), participation in highway trash pickup (Oklahoma), acknowledgment of local individuals and groups through a chapter award program (Metropolitan Atlanta), and sponsorship of a high school scholarship (Omaha-Offutt). Several chapters organize and conduct local conferences and workshops (High Plains, Puget Sound, and Wright Memorial).

Consider these creative ideas too. Take a tour of a baseball stadium and find out how they get their weather information (Denver-Boulder), visit a science museum (Chicago) to enhance your historical perspective, or take a tour of a water management district facility (North Texas) to broaden your knowledge of how your community works. The Los Angeles chapter holds an annual potluck dinner with members bringing videos and photos to share, while the University of Nebraska chapter has an annual picnic. Go storm chasing with the Greater Milwaukee chapter. Check local theaters for weather-related movies. Some chapters invite the winners of the local science fairs 
to give their presentations to the chapter. The Palmetto chapter hosts an annual mini-technical conference over a weekend, inviting members from neighboring chapters to participate. Other possibilities include recognizing a "Member of the Year" with a plaque or similar award, often at an annual banquet, or holding chapter contests with some fun weather-related paraphernalia as the prize. Contests could involve weather photography, date of first snowfall, first day over $100^{\circ}$, first freeze, or something else that is appropriate for the area. Showcase the talents of your own chapter members with a "Members Night."

Public Relations, Marketing, and Communication: Everyone is very busy, so why should someone join and be a part of your chapter? Your challenge is to link the Society's objectives with the needs and desires of your local chapter members. Get out and market your planned activities. Chapter officers should enthusiastically communicate their vision and objectives for their chapter. Leverage the Internet and local newspaper, radio, and television outlets to get your activities publicized. A chapter newsletter is a great way to publicize your events and spread useful information. Chapter events should improve chapter member knowledge of the atmospheric sciences and the relationship with and impacts on community customers, research, or forecasting activities. Enthusiasm and ability to articulate your chapter initiatives that bring your atmospheric science community closer together are far more important to a chapter's vibrancy and health than anything else. After setting up your next meeting, it is just as important to provide plenty of advance notice of your meeting dates. Use of variety of ways to publicize chapter activities; e-mail, links to Web sites, and colorful flyers are a few options. At the beginning of the year, consider a mass mailing to current and other possible chapter members with proposed chapter activities and a survey with a stamped return envelope to reenergize participation. AMS Headquarters can provide a list of national members' names and addresses and as discussed below will even pay for the cost of one mass mailing a year per chapter. You could then send a personalized letter inviting them to join local chapter activities. Consider door prizes to liven participation and name tags to foster group cohesion and fellowship.

Outreach to Your Chapter Members and Community: Your goal should be to provide value to your members and community. Local chapters are the
AMS's representative and link in each of our communities. Treat each chapter meeting and activity as an opportunity to educate each other, foster lifelong professional and personal relationships, and provide a valued service to your community. Consider sponsoring a forum to educate teachers and other educators about the atmospheric sciences and to motivate their desire to teach their students about meteorology and its relationship and importance to the world around them. Don't forget to meet needs in your community. Sponsor a scholarship for top performers in school, a blood drive to help meet local and regional needs, seize opportunities to mentor local teenagers, provide weather radios to local schools, spearhead a banquet for top school performers, or learn how airport authorities use and the importance of timely an accurate weather forecasts. Your only limitation is your imagination and ingenuity.

Leverage the Vast Resources of the AMS Headquarters: The AMS Headquarters has a tremendous array of information to assist local chapters. The AMS's Local Chapter Web site (http://www. ametsoc.org/AMS) has a wealth of information to assist local chapters. Noteworthy items on this Web site include a Local Chapter Officer's Handbook, which summarizes essential information concerning the Society and local chapters; the names, telephone numbers, e-mail addresses of important contacts at AMS Headquarters; a section on program ideas for local chapters; a directory of every AMS local chapter and student chapter, which includes telephone numbers and e-mail addresses for chapter officers; and information about chapter news or activities that could be helpful to other chapters. The best part of the AMS Headquarters help is someone dedicated to serve chapter needs. Kelly Garvey serves as the local chapter point of contact at AMS Headquarters. She can be reached at Marketing/Special Programs Manager, American Meteorological Society, 45 Beacon Street, Boston, MA 02108-3693; telephone: 617-227-2426, ext. 215; fax: 617-742-8718; e-mail: kgarvey@ametsoc.org. AMS Headquarters will also support one mailing per chapter per year to all AMS members in the local chapter's area. The Bulletin has a section on chapter news dedicated to local chapter activities and events. In addition, specific articles designed to enhance chapter activities are provided and authored by the AMS's Local Chapter Affairs Committee (LCAC). To help recognize outstanding local chapters, the AMS Council has just recently approved an award for "Local 


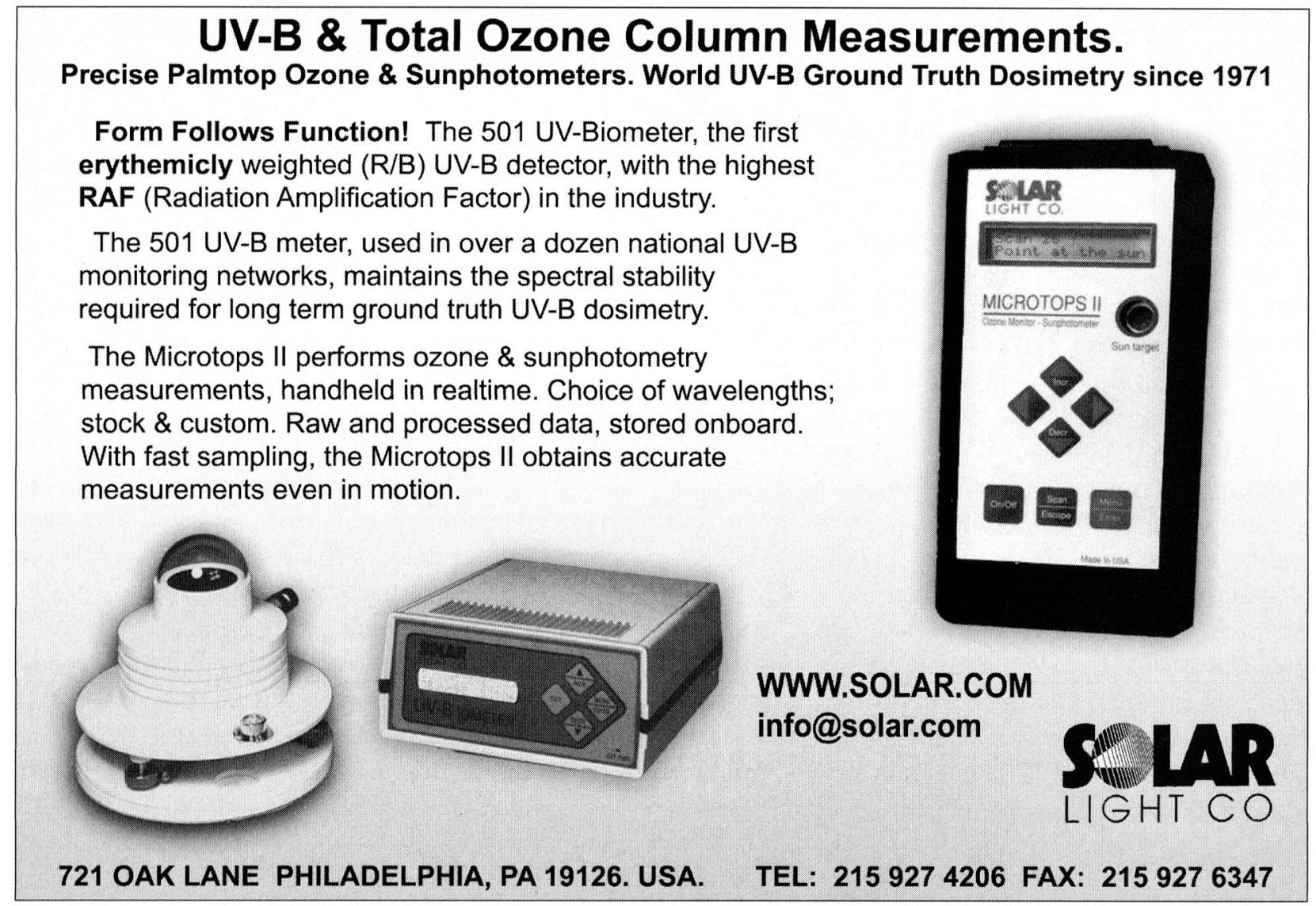

Chapter of the Year" and "Student Chapter of the Year." Nomination packages will be due by 1 May of each year to the AMS Headquarters Local Chapter Affairs representative. At the AMS Annual Meeting, local chapters are afforded several opportunities to display their initiatives, to meet other chapter officers, and to meet with professionals in our field. Local chapters are provided a highly visible space to display posters or other information about their chapter to the
Annual Meeting participants. The LCAC sponsors a breakfast for local chapters to facilitate an exchange of ideas. Later during the week, the LCAC also holds the popular student mentors luncheon that provides an opportunity for atmospheric science students to meet with and discuss career opportunities with weather professionals. If you are not involved in a local chapter, maybe it is time to look into what you are missing.Major Ken Carey. 